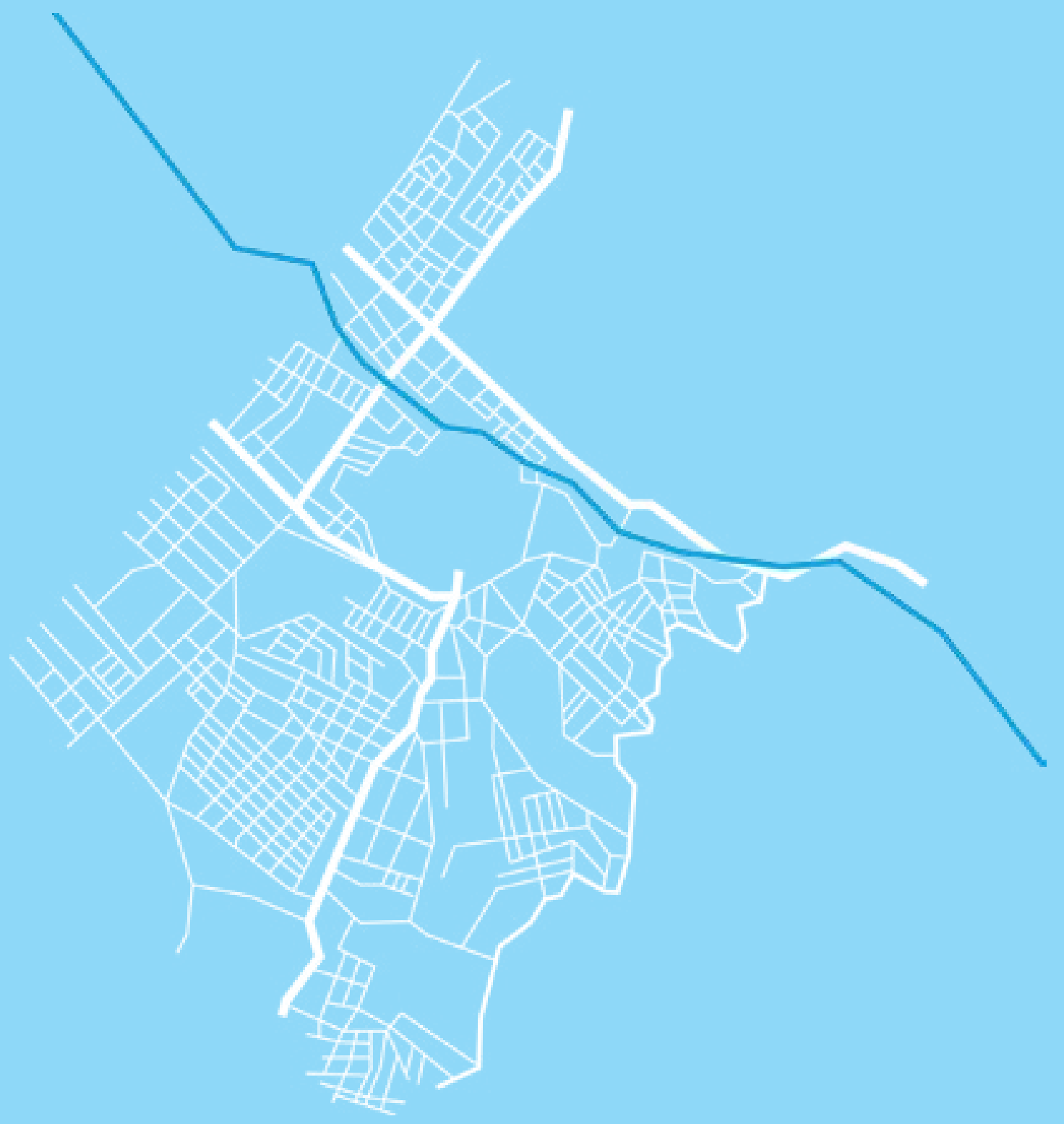

\title{
La calle no se dobla por la esquina sino por el centro: del agua y el territorio
}

The street does not bend around the corner but the center: the water and the land A rua não se dobra a esquina, mas o meio: o água e o terra

Fabiola Moreno C. 
La calle no se dobla por la esquina sino por el centro: del agua y el territorio

\section{Fabiola Moreno C. ${ }^{2}$}

1 Fragmento del marco teórico del proyecto "Un Viaje, una ruta... un mapa: didácticas del territorio", elaborado en el marco del proyecto "Sistematización de Experiencias Pedagógicas” del Instituto para Investigación Educativa y el Desarrollo Pedagógico IDEP, 2009.

2 Licenciada en Ciencias Naturales de la Universidad Pedagógica Nacional. Magister en enseñanza de las Ciencias Naturales y Exactas, Universidad Nacional de Colombia. Docente del Colegio Técnico Tomás Rueda Vargas. Correo electrónico: fabiolamore@gmail.com

Fecha de recepción: 24 de febrero de 2015 / Fecha de aprobación: 3 de abril de 2015.

\section{Resumen}

El presente artículo expone el proceso de una experiencia pedagógica fundamentada en una perspectiva contemporánea del pensamiento, ella introduce criterios de integralidad en la aproximación al estudio del territorio conforme a la metáfora del fractal; visión en la cual el todo y las partes se hallan en interacción dinámica y contradictoria. La experiencia comienza en el aula de clase, fue trabajada recurriendo a problemas contextuales, es decir, problemáticas cercanas a la localidad cuarta de Bogotá, San Cristóbal, concretamente, preguntas relativas a los procesos de degradación ecológica.

\section{Palabras clave}

Agua, territorio, ruta, aula, cruzar, calle.

\section{Summary}

This paper presents the process of teaching experience based on a contemporary perspective of thought, she introduces criteria of comprehensiveness in the approach to the study of the territory under the metaphor of fractal; vision in which the whole and the parts are in dynamic and contradictory interaction. The experience begins in the classroom, was worked using contextual problems, ie, problems near the town quarter of Bogotá, San Cristobal, namely, questions concerning ecological degradation processes.

\section{Key words:}

Water, land, map, classroom, cross street.

\section{Resumo}

Este artigo apresenta o processo de experiência de ensino com base em uma perspectiva contemporânea do pensamento, ela introduz critérios de abrangência na abordagem ao estudo do território sob a metáfora do fractal; visão na qual o todo e as partes estão em interação dinâmica e contraditória. A experiência começa na sala de aula, foi trabalhado com problemas contextuais, ou seja, os problemas de perto o trimestre cidade de Bogotá, San Cristobal , ou seja, questões relativas aos processos de degradação ecológica.

Palavras chave:

Água, terra, mapa, sala de aula, rua transversal. 


\section{Introducción: del agua y el territorio}

E ta experiencia inicia con la necesidad de recurrir a un nuevo enfoque para visibilizar e indagar por las interacciones ocultas que se establecen en el territorio (incluyendo a la escuela) cuando se abordan desde perspectivas reduccionistas. El proyecto se propuso estudiar el territorio desde los modelos fractales, ya que hacerlo posibilitará un análisis complejo de la realidad física, cultural, geográfica, política, histórica, etc. En efecto, el territorio tiene características fractales, pues la ciudad y la sociedad manifiestan, en diferentes escalas, elementos de auto-organización y auto-poiesis, donde los ciudadanos, en una suerte de dialéctica, le dan vida al territorio y éste a su vez se la posibilita a sus habitantes. El territorio es un concepto entendido de diversas maneras:

Para las ciencias naturales el territorio sería el área de influencia y dominación de una especie animal, la cual lo domina de manera más intensa en el centro y va reduciendo esta intensidad en la medida en que se aproxima a la periferia, donde compite con dominios de otras especies ${ }^{3}$.

Por su parte, las ciencias sociales entienden el concepto de territorio, adaptándolo a la especie humana, como el espacio de dominación, propiedad y/o pertenencia de los individuos o las colectividades, sean estas naciones, estados o pueblos; es decir, como espacio sometido a unas relaciones de poder específicas; esta fue la herencia que recibió la Geografía del Estado-Nación como proyecto y como cultura política.

Esta tradición de pensamiento entiende el territorio como un espacio dominado por los sujetos (sean individuales o colectivos), al revés de otras culturas, donde los sujetos pertenecen al territorio, forman parte de él, como se expresa en el hecho, por ejemplo, de que los U'wa se nieguen a negociar el Bosque Samoré, porque para ellos vender el territorio sería igual que vender la madre, es algo que simplemente no está en venta. La noción resulta incomprensible desde cualquier concepción antropocéntrica, como la judeocristiana, por ejemplo, que asume a los seres humanos como los "amos y señores del universo", y, en consecuencia, como los propietarios del territorio.

3 Correia de Andrade, Manuel, 1996.
En el actual momento de desarrollo de la ciencia y el pensamiento, la "Teoría de sistemas" y la "Teoría de la complejidad", han traído consigo la reconceptualización del territorio como campo relacional, multivariado y complejo, y han permitido el desarrollo de nuevas metodologías para abordar la producción de conocimiento sobre el territorio, acordes con su nuevo estatuto ontológico, entre ellas, la de fractales, para producir conocimiento sobre el territorio como realidad sistémica y multivariada: "[...] inmersa en relaciones y conexiones, conexiones entre la gente y el entorno, conexiones entre y a lo largo de lugares, conexiones entre la gente y los lugares" (Hanson, 1997).

El territorio no es simplemente lo que vemos, no solo es montañas, ríos, valles, asentamientos humanos, puentes, caminos, cultivos, paisajes; también es el espacio habitado por la memoria y la experiencia de los pueblos, producto de un largo y paciente proceso de conformación que ha tomado muchos años y muchas vidas, que tiene las huellas de los antepasados, pero también las nuestras. Por eso, aprender a leerlo y descifrarlo puede enseñar mucho sobre cómo resolver los problemas, conflictos, dudas e incertidumbres que enfrentamos en el presente.

Así, nace el proyecto "Un viaje, una ruta un mapa: didácticas del territorio", reconocido como una experiencia significativa, en tanto que enseña otra forma de vivir la ciudad y el acto educativo; es decir, una experiencia que propende por el uso pedagógico de la ciudad, tal como se estipula en una de las ocho herramientas para la calidad del Plan Sectorial 2008-2012: "Educación de calidad: Derecho de todos para vivir mejor".

\section{Desde el territorio: desdibujar o trazar una ruta en aula}

En su devenir, las sociedades construyen territorios a la medida y a la manera de sus tradiciones, pensamientos, sueños y necesidades; ellos significan mucho más que un espacio físico poblado por distintas formas de vida que se relacionan, cooperan y compiten entre sí, ya que es un espacio construido por los distintos pueblos y, como tal, siempre está habitado por sueños y memorias, construido por quienes lo habitan, dándole color, rasgos, palabras y consciencia, es decir, una manera de ser y de sentir que se "marca en el rostro" (Chopra, 1995, p. 201).

Por otra parte, en el territorio se cumple también aquella ley fundamental de la ecología, de que cada cosa está relacionada 
con todas las demás, propiedad que caracteriza a los sistemas abiertos y complejos y al territorio como uno de ellos. Por lo tanto, entenderlo y llevarlo al aula significa trazar una ruta que transciende el currículo, ya que re-significa las formas de enseñar y aprender desde una mirada no reduccionista, donde se resquebraja progresivamente el edificio del saber y, con él, toda imagen acumulativa del desarrollo de los conocimientos.

Hacerlo, implica edificar un espacio donde los conceptos circulan, renacen y se transforman lejos de su punto de partida; donde se desmorona el lenguaje unitario de la síntesis totalizante; donde aparecen nuevos procedimientos e imágenes entre lo individual y lo colectivo, lo local y lo global; donde se dan nuevas comunicaciones, interconexiones e híbridos, entre la multiplicidad heterogénea de los lenguajes, de los universos locales; donde los niveles de organización se abordan desde una nueva dimensión: los fractales, que permiten encontrar relaciones entre la totalidad social y la local y, con ello, la forma como se reproduce lo sociedad en esos niveles de realidad.

Desde este enfoque, entender la localidad de San Cristóbal tan solo desde la simple descripción de sus avenidas, de su arquitectura, sin tener en cuenta a la comunidad y sus múltiples interconexiones con el territorio, conduce a una concepción fragmentada del conocimiento. Ahora bien, surge un problema: ¿Cómo abordar el territorio desde diversas miradas en la escuela, dadas las formas de trabajo que allí se adelantan donde es clara la concepción clásica predominante, la aproximación reduccionista y la puesta de límites rígidos entre las disciplinas?

En efecto, así es como hemos aprendido a pensar, separando un objeto de su entorno y aislándolo con respecto al observador. Nuestro pensamiento es disyuntivo y reductor: buscamos la explicación de un todo a través de las partes, queremos eliminar el problema de la complejidad. Obstáculo profundo que obedece al arraigo de una forma de pensamiento que se ha impuesto a nuestra mente desde la infancia, consolidándose posteriormente en la escuela y la universidad, sirviendo de paradigma a los expertos y especialistas.

Dentro de este contexto, los modelos de pensamiento que han imperado hasta el momento, como el racionalista y el empirista, han influido en los contenidos y estrategias de la educación escolar, lo cual ha conducido a un sinnúmero de problemas, entre ellos la "linealidad" del conocimiento, que se organiza en currículos y programas de estudio ajenos a los procesos de creación, comunicación e intereses vividos en la experiencia.

En oposición con esta forma de enseñanza, en la cual el avance se da en un orden muy bien definido que se puede asimilar a una línea recta, se propone una compleja, no en el sentido de dificultad, sino en el del reconocimiento de la multiplicidad de variables que entran en juego cuando se aborda un problema.

Pensando en ello, es posible adoptar a los fractales como una nueva imagen para el proceso de aprendizaje y el estudio del territorio, encontrando relaciones entre éste y los eventos que se suceden como parte y reflejo del mismo. Supongamos que desde el territorio se desea procurar el aprendizaje de una manera tal que posibilite al estudiante explorar la red, siguiendo un nivel hasta el otro de acuerdo con sus múltiples interconexiones, conformando una suerte de holograma, tal como se evidencia en los diferentes niveles de organización de lo viviente, en los cuales todas las partes están sinérgicamente en interacción recíproca.

Así, la indagación del estudiante se daría, por ejemplo, con una pregunta preliminar que seguiría de acuerdo con las necesidades que se vayan presentando, de manera que las respuestas alcanzadas darían origen a nuevas preguntas, en una suerte de bucle recurrente mediado por las interacciones presentes en los ambientes considerados, ya sean físicos, culturales o sociales.

Por otra parte, desde nuestro ámbito, y en esta nueva perspectiva, el conocimiento que se genera del territorio lleva a la resignificación del lenguaje, que pasa a estar construido sobre las bases de la lógica por interacciones, mirada que implica interpolar e interpretar los diferentes niveles de realidad, ya que nada sucede fuera del territorio. Resignificar y aprender desde el territorio trasciende los programas de enseñanza y rompe las fronteras de las disciplinas que "se dictan" como una lista de temas fragmentados que el estudiante debe seguir, uno por uno, como condición para permanecer en la institución escolar. Por ello, esta nueva visión apunta a un cambio radical de los enfoques sobre el saber y el aprendizaje, y lleva a mirar con reserva el conocimiento usual y su pretensión de verdad y universalidad, lo que implicaría ubicar de nuevo las condiciones que hacen posible su emergencia y sus características de regulación.

\section{Sin poder cruzar la calle}

"Un viaje, una ruta, un mapa" es una propuesta de aula en donde se observan aspectos de la vida cotidiana pretendiendo superar el tradicional modelo didáctico basado en la relación maestro-estudiante-contenido, a partir de la analogía con el fractal y sus relaciones de interdependencia con su entorno (como el 
tronco y las ramas de un árbol), desde el conocimiento reflexivo y crítico de su realidad biofísica, social, política, económica y cultural, teniendo en cuenta el territorio, la cultura y su memoria histórica.

Al plantear el estudio de los fenómenos relativos a las múltiples afectaciones del Río Fucha con la comunidad, no se expone un tópico propio de la ecología o un tema del área de biología, sino una problemática social que pone de presente la desigualdad de oportunidades y tiene implicaciones en la convivencia, en lo técnico y lo ambiental. El problema exige asumir responsabilidad social con el territorio, en contraposición a la indiferencia ciudadana frente a los fenómenos que traspasan las fronteras de la escuela; este evento es posible si desde el aula se asumen formas de trabajo que lleven a la construcción de actitudes y valores de responsabilidad y respeto hacia todas las formas de vida, aspirando con ello a traspasar el escenario escolar mediante la transformación de estas disposiciones en criterios de acción para los participantes.

\section{Agua, agua y más agua: Del desbordamiento del Río Fucha}

La geografía de la localidad cuarta de San Cristóbal es un verdadero laberinto de calles que suben y bajan en el suroriente de Bogotá; se precipitan desde los $3.150 \mathrm{msnm}$ y caen en el plan del 20 de Julio a 2.600 metros. A diario el Río Fucha y las quebradas Morales, La Chirosa y El chorro de Silvino hacen el mismo recorrido, atraviesan esa zona de oriente a occidente, entre barrios populosos y empinados, buscando desembocar en el Tunjuelo.

El Río Fucha nace en el páramo de Cruz Verde, a pocos minutos de Bogotá, sus aguas cristalinas descienden alegremente dando tumbos entre las piedras hasta alcanzar el primer asentamiento humano, a partir de allí el río se convierte tristemente en botadero de toda clase desechos. Uno los problemas asociados al río son las constantes inundaciones, prueba de ello es la muestra de informes de corte ambiental (como aforos pluviométricos y niveles de volumen de agua), o el efecto del proceso de desarrollo de la ciudad. En 2007, tanto el diario El Tiempo como otros medios de comunicación, publicaron la noticia del desbordamiento del Río Fucha, informando acerca del daño de viviendas y el perjuicio para sus habitantes. "Escapando de la inundación",
"Organismos de control atienden la emergencia", "Caos en la Capital", "Tratando de salvar sus pertenencias" (El Tiempo, 2 de Abril, 2007), fueron algunos de los titulares que se pudieron leer en ese momento.

Si bien es cierto que las lluvias son la causa principal de las inundaciones, hay otros factores igual de importantes:

Exceso de precipitación. Los temporales de lluvias son el origen principal de las avenidas. Cuando el terreno no puede absorber o almacenar el agua que cae, ésta resbala por la superficie (escorrentía) y sube el nivel de los ríos.

Rotura de presas. Cuando se rompe una presa, toda el agua almacenada en el embalse es liberada bruscamente y se forman grandes inundaciones, muy peligrosas.

Actividades humanas. Los efectos de las inundaciones se ven agravados por algunas actividades humanas:

- $\quad \mathrm{Al}$ asfaltar cada vez mayores superficies se impermeabiliza el suelo, lo que impide que el agua se absorba por la tierra y facilita que las aguas lleguen con gran rapidez a los cauces de los ríos, a través de desagües y cunetas.

- La tala de bosques y los cultivos que desnudan al suelo de su cobertura vegetal facilitan la erosión, con lo que llegan a los ríos grandes cantidades de materiales en suspensión que agravan los efectos de la inundación.

- Las canalizaciones solucionan los problemas de inundación en algunos tramos del río, pero los agravan en otros a los que el agua llega mucho más rápidamente.

- La ocupación de los cauces por construcciones reduce la sección útil para evacuar el agua y reduce la capacidad de la llanura de inundación del río. Las aguas suben a un nivel más alto y llegan en mayor cantidad a los siguientes tramos del río porque no han podido ser embalsadas por la llanura de inundación, provocando mayores desbordamientos. Por otra parte, el riesgo de pérdidas humanas y de daños personales es muy alto para las personas que viven en esos lugares. Como siempre, la fuerza de la naturaleza se impone sobre el hombre y la ingeniería. 
En conjunto, se puede reflexionar, no solo sobre el por qué de las inundaciones, sino sobre el conocimiento del río y las características medioambientales que lo rodean ¿Se conocen las plantas nativas del Río Fucha?; ¿quién decide y a favor de quién?; ¿se conoce la dinámica de la red hídrica de Bogotá, o se apunta a solucionar un nodo dentro del sistema?

Según la empresa de acueducto y alcantarillado, cuando llueve muy fuerte: el Río Bogotá sube y el Río Fucha pasa en la creciente de un volumen de agua de $42 \mathrm{~m}^{3} / \mathrm{seg}$., a $52 \mathrm{met}^{3} / \mathrm{seg}$. Por este motivo, el alcantarillado no alcanza a descargar al Río Bogotá; eso hace que, por un lado, se remanse y se dé el encharcamiento en las calles y que, por otro, el alto nivel del Río Bogotá no deje al Río Fucha descargarse, provocando que el sistema se detenga y el nivel del agua suba inundando las partes bajas de Fontibón.

Ante esta problemática surgen diversas explicaciones: Mágicas: "El río tiene memoria y recobra su trayectoria" y Tecnócratas: "Los modelos desarrollados fallan en los diseños". Definiciones que no alcanzan a dar solución al problema, pues éste sugiere varios niveles de análisis: el ambiental (efecto del río sobre la ciudad, eventos atmosféricos); el social (los habitantes de la cuenca) y el urbano (el crecimiento de la ciudad sobre el río). Existen, por supuesto, otras aproximaciones. Un estudio completo implicaría evaluar los conflictos sociales relacionados con la explotación del recurso, la tenencia de tierra, los intereses políticos y los procesos de poblamiento. La complejidad y vastedad del tema no se abarca en este escrito.

Desde la comprensión (Segura, 2002), el problema es de todos y tiene que ver con la forma como nos relacionamos, con las conexiones con nuestra propia vida y la forma de vivir en sociedad. Esta no es una cuestión de la Biología, ni del ciclo de agua, va de la mano de diversas disciplinas que pueden contribuir a su comprensión. En este contexto, cobran fuerza planteamientos holísticos que conciben la realidad desde una visión compleja, pues considera múltiples variables como el entorno, la cultura y el contexto del estudiante, lo que conduce a reconocer cómo nuestra manera de vivir es consecuencia de nuestros actos al pensarnos de manera individual.

De este modo, la presente experiencia pretende pasar de la idea clásica de las calles, de entenderlas como lugares que no se afectan ni se dejan afectar, donde los cuerpos escriben un cuerpo que nadie puede leer porque escapa a toda lectura, a entenderlas como un territorio donde los trazos de esas escrituras, infinitamente entrecruzadas, componen una historia múltiple de autores, espectadores, de tiempo, de trayectorias y de alteraciones que escapan de toda disciplina, de toda clasificación, de toda jerarquización. La calle no se dobla por la esquina sino por el centro.

\section{Escapando de la inundación}

A la luz de los ejemplos señalados, esta es una aproximación para crear un contexto que conduzca a que la acción educativa salga del marco escolar. Esta acción hace que los estudiantes se interesen por la colectividad y los convierte en partícipes de sus actividades. Tomar parte de las actuaciones locales es un elemento formador por excelencia (realización de contraproyectos urbanos, acciones en defensa de lugares naturales o urbanos), pero bajo la condición de que los términos del debate sean propuestas de actuación y se fundamenten en una reflexión calmada y profunda de competencias reales. Una vez situados los estudiantes en la vida cotidiana, y enfrentados con los problemas de su localidad, es cuando se sienten preocupados por la calidad del medio y cuando actúan para preservarlo y mejorarlo.

\section{¿Cómo se trabaja?}

En el espacio del proyecto "Un viaje, una ruta... un mapa", se generó un ambiente dentro y fuera del aula, libre y espontáneo, en donde los niños se movían, manipulaban, gritaban y comentaban con los compañeros de otras mesas de trabajo, comprobando que existen otras maneras de mirar las mismas cosas, que no todos comparten las mismas opiniones y que el trabajo en grupo supera al individual, generando la necesidad de crear y argumentar, de defender ideas y justificar las opiniones; al hacerlo, se ven retados a aclarar sus pensamientos.

\section{¿En dónde empezó todo?}

Todo comenzó con la idea de construir un ambiente de aprendizaje, curiosidad y creación, donde los estudiantes se dieran cita cada día para conocer el lugar donde viven y sus problemáticas. Un día comenté a estudiantes y compañeros de trabajo la idea de salir con 80 estudiantes para emprender dicha búsqueda, ante la acogida de la propuesta comenzamos a gestionar espacios, a reconocer con anterioridad el sitio, a visitar y abrir la escuela para que fuese afectada por integrantes de la comunidad. 


\section{Momentos de la actividad}

Inicialmente, se propone a los alumnos que elaboren imágenes o representaciones del campo relacional en que transcurre su vida cotidiana. Así, comienzan por identificar y representar los elementos, las relaciones, las dimensiones y las tendencias que caracterizan su territorio vivido y percibido.

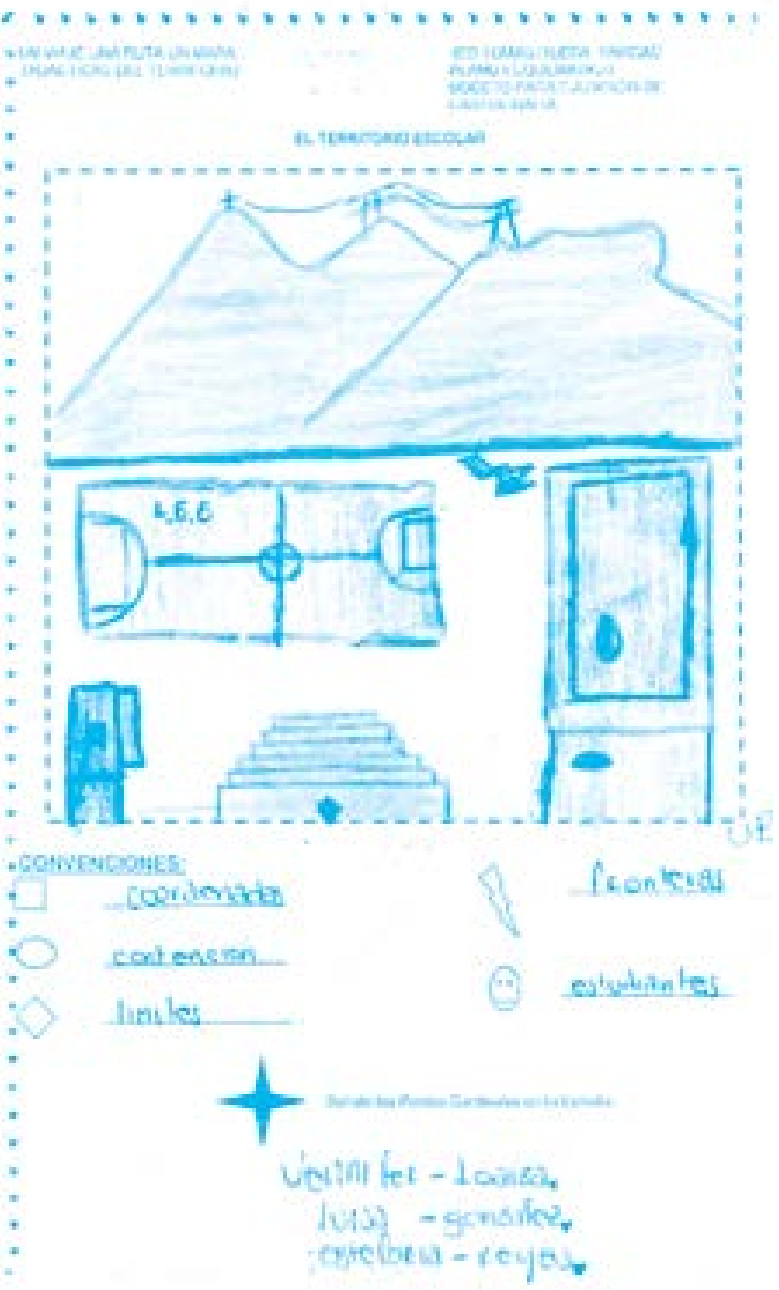

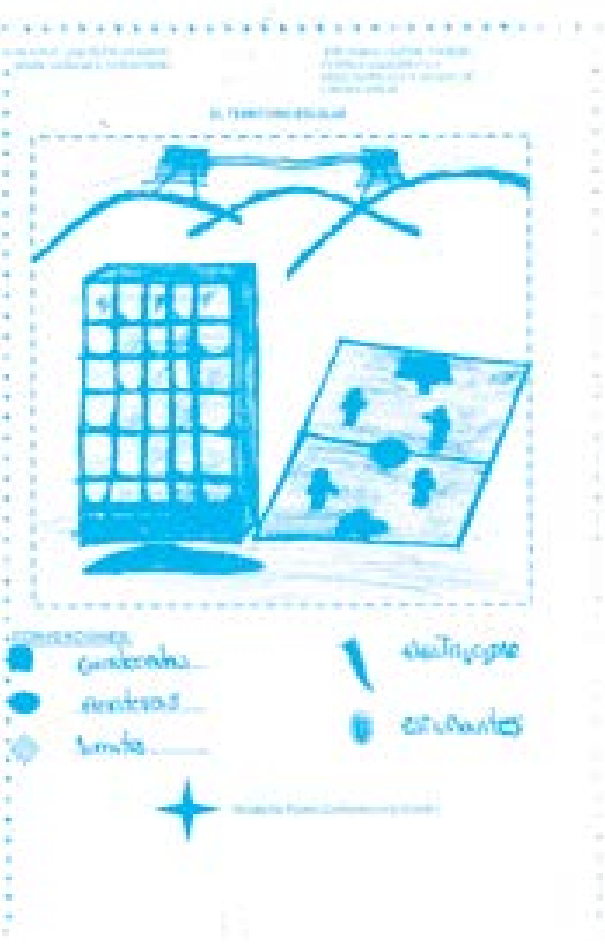

Figura 1. Dibujos desarrollados durante el ejercicio

En este momento del proyecto los alumnos detectan algunos problemas relacionados con la territorialización del espacio escolar; avanzan en el reconocimiento de los conflictos que dinamizan la localidad y los riesgos y amenazas propios de los vínculos con el espacio extraescolar, en este caso, su barrio. Los estudiantes hacen representaciones gráficas de sus vivencias y sus imaginarios e identifican los problemas, éstos son plasmados en dibujos y mapas que, junto con relatos creados durante el proceso de construcción, dan cuenta de diferentes visiones sobre el territorio, la forma como ellos lo asumen y su relación con los otros. Al respecto del agua manifiestan:

- El agua es una fuente hídrica que nos sirve para muchas cosas, el agua es vital para el ser humano, ya que sin esa moriríamos; algunas fuentes hídricas son el alcantarillado, las quebradas y el río.

- El agua es indispensable para vivir y nos ayuda. La laguna de Aguas Claras, la Reserva de la Cecilia y 
el Río Aguas Claras.

- Sustancia cuyas moléculas están formadas por la combinación de un átomo de oxígeno y de hidrógeno e inodora.

- Tego seca de mi casa un río y el plogema es que le arojan basura.

A continuación, se invita a un líder de una organización social de la localidad de San Cristóbal para que converse y socialice con los estudiantes las dinámicas del barrio, de los escenarios, de los tiempos y del significado y movilidad del territorio. La salida comienza con estudiantes cuya edad oscila entre los 10 a 15 años de edad, aunque en las reflexiones desarrolladas en el aula incluyeron una población de estudiantes con una edad de entre 10 y 12 años. En el aula de clase se procede nuevamente a leer el espacio recorrido. Cada uno de los estudiantes evoca cómo se vive el espacio; se les solicitó que elaboraran una historia y describieran esta situación:

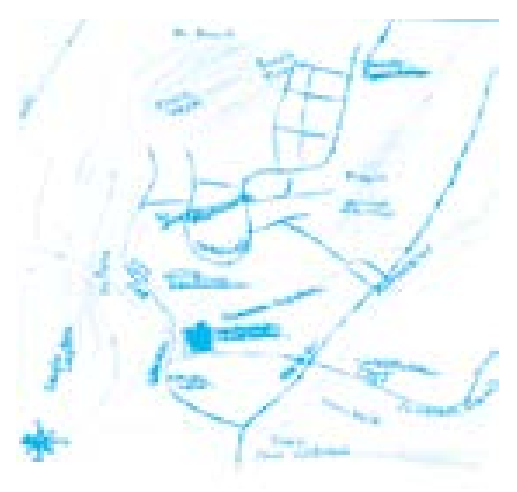

Figura 2. Mapa desarrollado durante el ejercicio
Después de evocar lo visto en su barrio, calles y avenidas, se hizo un análisis de la imagen realizada, esta lectura se orientó a partir de tres puntos de vista: Vista aérea (maqueta), vista aérea vertical (mapa) y vista frontal (corte o transecto). Con estas actividades se querían cubrir todas las relaciones posibles entre un punto de vista y un modo de representación, ejercicio que no resultó tan complejo porque se trataba de espacios que eran familiares para los estudiantes.

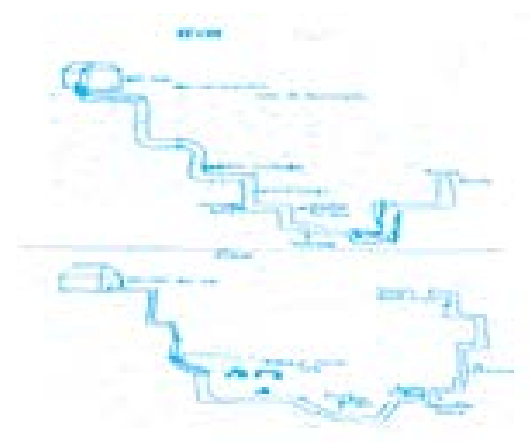

Figura 3. Mapa realizado durante el ejercicio

\section{Los mapas ahora los vivimos: yo afecto, tú me afectas}

Debido a la imposibilidad de consolidar la información en un solo mapa, se propuso trabajar a partir de como mínimo cuatro mapas. El primero se orientó al reconocimiento del territorio físico y económico, la relación población-naturaleza y población-producción. El segundo, identificaba la infraestructura: servicios, vías, caminos, iglesias, redes, espacios de encuentro; el tercero, plasmaba las relaciones entre sujetos y escenarios; en el cuarto mapa se identificaron los conflictos, riesgos y potencialidades. Durante este momento se realizó una plenaria en la que cada grupo de estudiantes mostró los resultados y realizó un cruce de mapas consolidando la información planteada. Esto se completó con relatos y así se caracterizó el territorio en colectivo. 


\section{Trabajo de campo}

Este espacio se dedicó a la recopilación de información directamente del escenario natural de los estudiantes; buscando que observaran su espacio de forma detallada e intencionada, concentrándose en aspectos relacionados con el desequilibrio ambiental en el Río Fucha. Además, se les solicitó que realizaran interrelaciones desde aspectos como la selección de sensaciones, de degustar y catar el espacio. Así, se procedió a tomar notas de campo que luego serían organizadas en un diario. El recorrido buscaba contribuir al reconocimiento del territorio, evocar la memoria y confrontar la información con los mapas realizados en clase.

Recorrer el territorio permitió su reconocimiento, la posibilidad de confrontar lo planteado en el aula, para quienes tenían un conocimiento fragmentado, y verlo, sentirlo, apropiarse de forma integral; así se fueron construyendo los aportes. Los imaginarios de los estudiantes sobre el Río Fucha señalan una profunda preocupación por las inundaciones y la contaminación, entendiendo esta última como consecuencia de un mal ordenamiento, de la estigmatización que sufre el sur de la ciudad y del tratamiento que le dan los pobladores a sus recursos hídricos.

\section{Vías de pensamiento}

En este apartado se describe el momento en el que se pasa de un análisis teórico a actuaciones concretas para dar solución a un problema, resumiendo, se dio de la siguiente forma:

1. Reconocer que existe un problema: desbordamiento del Río Fucha.

2. Reunir documentación sobre el problema y dominarlo.

3. Construir un inventario claro de argumentos a favor y en contra; establecer el papel de los diferentes grupos: responsables políticos y asociaciones de defensa de la localidad.

4. Concebir un plan de resolución del problema que desemboque en soluciones alternativas.

5. Establecer una planificación realista para emprender la actuación y concretar hechos.
Esta etapa esbozó un cuadro de las actividades humanas, perceptibles por medio de indicadores vistos en el terreno, y permitió señalar una serie de hipótesis sobre los posibles problemas en el territorio.

\section{Tratando de salvar las pertenencias}

\section{De la ruta al aula}

El ambiente que se construya en el aula es determinante para construir otra mirada de mundo, siguiendo los planteamientos de Landinez Fanny (2005):

El Ambiente Educativo, entendido como el resultado del entramado de interacciones, entre los actores escolares con el currículo, el conocimiento, el espacio físico, entre otros, puede constituirse, o bien en un camino con múltiples posibilidades de transformación escolar en la convivencia, generando ambientes de confianza, o en un camino único con mínimas posibilidades de transformación, produciendo medidas de control permanentes.

Acerca de los grupos y la construcción de un ambiente por interacciones en el aula de clase, se afirma que:

Para la conformación del grupo no es suficiente unir pupitres, sino propiciar un ambiente en el que las actividades propuestas convoquen a los niños a hablar, a discutir, a hacer preguntas entre sí y a trazar metas comunes, donde el conocimiento no es una actividad individual, sino una búsqueda compartida, esto no implica la desaparición de la individualidad, sino que, por el contrario, se reconoce en la individualidad y posibilidad de cada sujeto. La conversación que allí emerge con otros permite apropiarse de formas distintas de interpretar los fenómenos o los eventos de lo cotidiano, y es en el grupo que se consolida la posibilidad de articular estas vivencias y replantear nuevas formas de leer el mundo, bajo la perspectiva de acciones pactadas, de ayuda y reconocimiento mutuo (Landinez Fanny, 2005).

Las siguientes preguntas de los estudiantes tuvieron su origen en el aula de clase, luego de hacer el recorrido por la ronda del Río Fucha, y fueron tenidas en cuenta para el diseño de la ruta de 
aprendizaje: ¿Cómo era este territorio?; ¿quiénes lo habitaban?; ¿cómo dejamos huella?; ¿quiénes viven ahora?; ¿por qué el río tiene espuma?; ¿los detergentes cambian el río?; ¿por qué no se ven peces?

En la siguiente clase la maestra llevó una plancha del Instituto Agustín Codazzi que presentaba la trayectoria del Río Fucha y las localidades por donde pasa. Acto seguido, invitó a los chicos a reconocer su territorio, a realizar cuatro tipos diferentes de mapas y a escribir sus imaginarios sobre los espacios, ubicando la escuela, los sujetos y las acciones desde una doble dimensión: localización y actitud de sus habitantes frente al entorno y usos y relaciones.

A medida que el río viaja, su vida se transforma y surge la preocupación: ¿Qué hacemos entorno a la vida del Río Fucha? Los estudiantes proponen penalizar a quienes boten basura al río, también están interesados en realizar acciones desde sus casas que lleven a la limpieza de este cuerpo de agua, de allí surge la idea de elaborar un jabón ecológico. La maestra lleva diferentes tipos de jabón, entre ellos, un jabón de tierra, y comenta que éste es elaborado por nuestros campesinos, a continuación pregunta a la clase si sabe para qué se utiliza, y surgen respuestas como: para dar brillo al cabello y para quitar la caspa; los estudiantes huelen el jabón y no les gusta, pero les llama la atención su envoltura, hecha con cáscaras de plátano, y preguntan por los materiales utilizados para elaborarlo; la maestra les cuenta que en la plaza le dijeron que estaba hecho con sebo, tierra y ceniza.

En medio de la discusión se pensó en elaborar un jabón artesanal aromatizado que contribuyera a no dañar el río. Se preguntó entonces por el procedimiento para la elaboración del jabón y se propuso adelantar una consulta bibliográfica sobre el método para hacerlo. La búsqueda abarcó aspectos como la historia, su clasificación, la diferencia entre jabones y detergentes y el impacto en la eutrofización de los cuerpos de agua, entre otros. Es en este momento que los alumnos, emocionados, llegan a la siguiente clase con bata de laboratorio y gafas protectoras, porque consultaron que la lejía era altamente cáustica; sus mamás envasaron aceite ya utilizado, sal y esencia; motivados, se pasaban entre ellos los aromas que habían escogido para hacer su jabón.

Un grupo de estudiantes sigue paso a paso las indicaciones y termina primero, lo muestran a sus demás compañeros quienes les piden que demuestren que saca espuma. Es allí donde surgen las preguntas: ¿Es posible utilizarlo para bañarnos?, ¿Cómo se sabe si el jabón está bueno?, ¿Qué nombre le colocamos a nuestro jabón?, ¿Cómo lo empacamos? ¿Qué es ph?, ¿Por qué la cinta medidora de ph cambió de color?, ¿Por qué el jabón limpia?, ¿Cómo el jabón puede matar los peces en el río? Múltiples cuestionamientos que se retomaron en las siguientes clases y que generaron discusiones, lo cual hizo evidente el interés por el problema y la búsqueda de soluciones. En esta línea de tiempo, se presentó la posibilidad de socializar la experiencia de realización de jabón con aceite usado de cocina en Expo-ciencia Juvenil.

A esta altura del proceso, las directivas del colegio Tomas Rueda Vargas asignaron rubros para la realización de jabones y los profesores de Ciencias Naturales y Matemáticas organizaron, junto a los estudiantes, espacios para la socialización de la experiencia. Luego se propuso a los estudiantes que formularan soluciones para que las personas que viven cerca de la ronda del Río Fucha no sufrieran las consecuencias de su desbordamiento. El resultado fue el diseño de un circuito, un modelo en pequeña escala para que, en caso de inundación, fuera posible indicar a los habitantes de la localidad cómo poder prevenir el daño a sus enseres. Así surge la propuesta de realizar una alarma, un detector de inundación, y comienza la búsqueda para construir un circuito que se active cuando el nivel de agua ascienda, que lleva a nuevos interrogantes: ¿En qué lugar de Bogotá se consiguen los materiales?; ¿qué es un circuito?; ¿cómo funcionaría?

Lo que presupone que los finales son el comienzo.

\section{La partida, el retorno: rupturas y tensiones}

La intención del proyecto fue promover el estudio del territorio mediante una aproximación alternativa que permitiera a los docentes ${ }^{4}$, estudiantes y miembros de la comunidad, acercarse al conocimiento de su entorno desde un proceso de interacción social, sin caer en reduccionismos, con el propósito de transformar las condiciones problemáticas. En efecto, la experiencia vivida nos permitió ver que el concepto de territorio se construye y se vive desde la cotidianidad de los niños y niñas, lo que permitió

4 Cabe resaltar la participación de los docentes del área de Ciencias Naturales y Matemáticas del Colegio Técnico Tomás Rueda Vargas, quienes actuaron en el recorrido de reconocimiento del Río Fucha, así como en el cuidado del stand de la institución en el evento convocado por la ACAC, Expo-Ciencia juvenil, octubre de 2007. 
a los estudiantes participar en la elaboración de su propio conocimiento a partir de sus intereses particulares.

No obstante, es necesario reconocer que esta forma de trabajo todavía presenta dificultades y tensiones en la convivencia escolar, pues exige aprender a trabajar en equipo y a tramitar, de forma fraternal y razonada, las diferencias para que no se conviertan en conflictos personales, situación frecuente en los trabajos de carácter innovativo. Por consiguiente, es necesario fortalecer el trabajo colectivo, superando la noción evolucionista del "más apto" y la machista, en la que unos se impones sobre los otros desde la descalificación de su saber por su condición de género.

En este marco, y a partir de la experiencia desarrollada, quedó demostrado que es posible construir otros modos de abordar la realidad escolar, a partir de las indagaciones que el docente realiza sobre su contexto; este hecho lleva a plantear nuevas metodologías y estrategias que estén de acuerdo con las búsquedas dinámicas, las cuales son posibles si están basadas en el "trabajo cooperativo, solidario y respetuoso de la diferencia". 


\section{Referencias}

Boada, M., y Quijano L. (2006). Ciudad, escuela, localidad. Bogotá.

IDEP. (2009). Un Viaje, una ruta... un mapa: didácticas del territorio. Bogotá: IDEP.

Landinez, F., Escobar, I., y Saavedra, S. (2005). El ambiente educativo: Un espacio a transformar. Bogotá: Escuela pedagógica Experimental.
Moreno, G., et al. (1998). La construcción de la confianza. Bogotá: Escuela Pedagógica Experimental- IDEP, pp. 130-150.

Segura, D. (2002). Del aula para el aula. Cuaderno 1. Bogotá: Alcaldía Mayor de Bogotá-CEPE. 